\title{
Measurement and calculation of Ta-182 in a spallation neutron target
}

\author{
G P Škoro, D J S Findlay and G J Burns
}

\section{Published version information}

Citation: G Škoro, D Findlay and G Burns. "Measurement and calculation of Ta-182 in a spallation neutron target." Nuclear Instruments and Methods A, vol. 961 (2020): 163641.

DOI: $\underline{10.1016 / j . n i m a .2020 .163641}$

(C2020. This manuscript version is made available under the CC-BY-NC-ND 4.0 Licence.

This version is made available in accordance with publisher policies. Please cite only the published version using the reference above. This is the citation assigned by the publisher at the time of issuing the AAM/APV. Please check the publisher's website for any updates. 


\title{
Measurement and calculation of Ta-182 in a spallation neutron target
}

\author{
G P Škoro, D J S Findlay and G J Burns \\ Rutherford Appleton Laboratory, Chilton, Didcot, OX11 0QX, UK
}

\begin{abstract}
Measured and calculated activities of ${ }^{182} \mathrm{Ta}$ in an ISIS spallation neutron target irradiated over five years are compared. The measurements were carried out by gamma-ray spectroscopy through the thick lead walls of a storage flask, and the calculations were carried out using MCNPX and CINDER-90. The agreement between measurement and calculation is good.
\end{abstract}

\section{Introduction}

It is important to be able to confidently predict radionuclide inventories in neutronproducing targets in spallation neutron sources, especially as such sources become more powerful [1-3], both as regards the activities of radionuclides themselves and the contributions that decaying radionuclides make to thermal decay power ('decay heat'). In the present paper we report work to measure the activity of ${ }^{182} \mathrm{Ta}$ in a tantalum-clad tungsten target removed after five years' irradiation from ISIS Target Station 1 (TS-1) [1].

On the one hand, since tantalum is a major component of the ISIS TS-1 target, and, since ${ }^{182} \mathrm{Ta}$ is produced largely by neutron capture on the ${ }^{181} \mathrm{Ta}$ that accounts for all but $0.012 \%$ of natural tantalum, ${ }^{182} \mathrm{Ta}$ must be one of the 'easier' radionuclides for Monte Carlo particle-tracking codes to deal with. On the other hand, however, it is a challenging task to calculate neutron production in a thick target and neutron moderation in a complex geometry (the ISIS TS- 1 target is located inside a beryllium reflector, in close proximity to ambient-temperature and cold moderators and neutronabsorbing materials along the neutron flight-lines). Further, the measurement of ${ }^{182} \mathrm{Ta}$ activity by gamma-ray spectroscopy has to be carefully timed; for too short cooling times after irradiation dose rates and gamma-ray backgrounds may be too high, whereas for too long cooling times the gamma-ray lines from 114-day-half-life ${ }^{182}$ Ta may have decayed into invisibility [4].

A comparison of measured and calculated values of ${ }^{182} \mathrm{Ta}$ activity is therefore of interest, not only for additional verification of the decay heat calculations for the ISIS TS-1 target $[5,6]$ but also for neutron-producing facilities such as the China Spallation Neutron Source [7] and the High Brilliance Neutron Source Project [8] where tantalum is important target material.

\section{Measurements}

At ISIS [1] neutron-producing targets on TS-1 are of a multi-plate heavy-water-cooled design consisting of twelve tantalum-clad tungsten plates, and a detailed diagram of the target is given in [4]. In May 2019 measurements of ${ }^{182} \mathrm{Ta}$ in an ISIS target irradiated 
by an $800 \mathrm{MeV}$ proton beam to 2903 milliamp-hours between 2009 and 2014 were made using two Canberra planar HPGe detectors (types BE2830 and BE3825). Since it was not practical for the HPGe detectors to look at the bare target (dose rate $\sim 0.5 \mathrm{~Sv}_{\text {hour }}{ }^{-1}$ at 1 metre), over six days between 22 and 28 May 2019 gamma-ray spectra from the target were measured through the thick walls of a storage flask containing the target. The flask is essentially a hollow lead $(\mathrm{Pb})$ vertical-axis right circular cylinder (height $140 \mathrm{~cm}$, diameter $93 \mathrm{~cm}$, walls $17 \mathrm{~cm}$ thick with $0.6-\mathrm{cm}$ and $1.5-\mathrm{cm}$ inner and outer steel skins). The HPGe detectors ${ }^{1}$ with their crystal axes horizontal were both positioned $100 \mathrm{~cm}$ from the surface of the flask and $60 \mathrm{~cm}$ above the floor, and the azimuthal angle between the lines from the axis of the flask to the detectors was $90^{\circ}$. A photograph is shown as Fig. 1. The target (in its stainless-steel pressure vessel) is suspended vertically (nose down) inside the flask, and the heights of the HPGe detectors corresponded to within $\sim 2 \mathrm{~cm}$ with the midpoint of the $38.7-\mathrm{cm}$ long target core inside the pressure vessel. Unfortunately, the practicalities of the complicated remote-handling operation necessary at ISIS for loading a highly radioactive into a flask mean that knowledge of the azimuthal orientation of the target about a vertical axis inside the flask becomes lost during the operation.

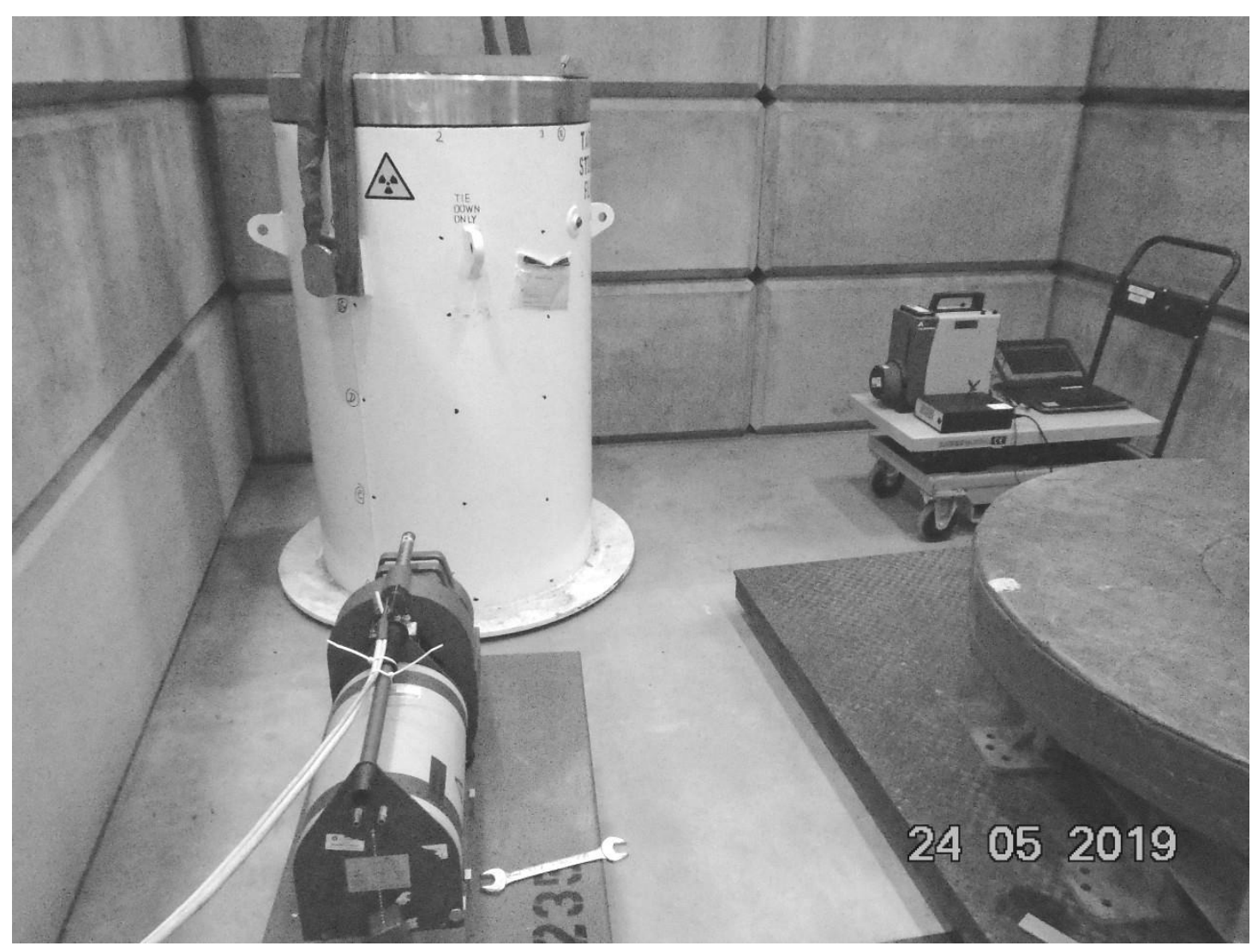

Fig. 1. Photograph of the flask containing the target and the two HPGe gamma-ray detectors (BE3825 towards the lower left-hand corner of the photograph, BE2830 towards the upper right-hand corner) as described in the text.

\footnotetext{
${ }^{1}$ The BE3825 detector was operated with Canberra's 2-inch $90^{\circ}$ collimation system in place.
} 
Fig. 2 shows a typical gamma-ray spectrum. In the neighbourhood of each of the four ${ }^{182} \mathrm{Ta}$ lines at $1121,1189,1221$ and $1231 \mathrm{keV}$, the measured data $S_{i}=S\left(k_{i}\right)$ where $k$ is gamma-ray energy and $i$ is channel number were fitted by $s_{i}=p_{i}+b_{i}$ where $p_{i}=$ $A\left(\operatorname{erf}\left(\left(k_{i}-k_{0}+\delta / 2\right) /(\sqrt{2} \sigma)\right)-\operatorname{erf}\left(\left(k_{i}-k_{0}-\delta / 2\right) /(\sqrt{2} \sigma)\right)\right) / 2$ represents the peak and $b_{i}=B\left(1+b_{1}\left(i-i_{\text {peak }}\right)+b_{2}\left(i-i_{\text {peak }}\right)^{2}\right)$ represents the underlying background, $p_{i}$ being the gaussian $A \exp \left(-\left(k-k_{0}\right)^{2} /\left(2 \sigma^{2}\right)\right) /(\sqrt{2 \pi} \sigma)$ integrated over $k$ between the lower and upper limits $k_{i}-\delta / 2$ and $k_{i}+\delta / 2$ of channel $i$ with width $\delta, A, k_{0}$ and $\sigma$ being the area, position and width parameter respectively of the peak, and $b_{i}$ being a quadratically varying background lying under the peak. The positions $k_{0}$ and widths $\sigma$ of the peaks were fixed by smoothly interpolating amongst the positions and widths of known peaks in the spectrum. Uncertainties in fitted parameters were established by repeatedly (100 times) perturbing channel counts $S_{i}$ by amounts randomly chosen from a gaussian distribution with standard deviation $\delta S_{i}$ where $\delta S_{i}$ is the uncertainty in $S_{i}$ and refitting, and then taking standard deviations of the sets of 'perturbed' parameter values. A typical fit, for the $1189-\mathrm{keV}$ line, is shown in Fig. 3, and count rates for both HPGe detectors are shown in Table 1.

\begin{tabular}{|ccc|}
\hline${ }^{182} \mathrm{Ta}$ line, $\mathrm{keV}$ & Count rate, $\mathrm{s}^{-1}, \mathrm{BE} 2830$ & Count rate, $\mathrm{s}^{-1}, \mathrm{BE} 3825$ \\
1121 & $0.0795 \pm 0.0075$ & $0.0033 \pm 0.0047$ \\
1189 & $0.0767 \pm 0.0053$ & $0.0224 \pm 0.0054$ \\
1221 & $0.1294 \pm 0.0047$ & $0.0459 \pm 0.0043$ \\
1231 & $0.0642 \pm 0.0048$ & $0.0263 \pm 0.0044$ \\
\hline
\end{tabular}

Table 1. Count rates for the four gamma-ray lines from ${ }^{182} \mathrm{Ta}$ for the two HPGe detectors.

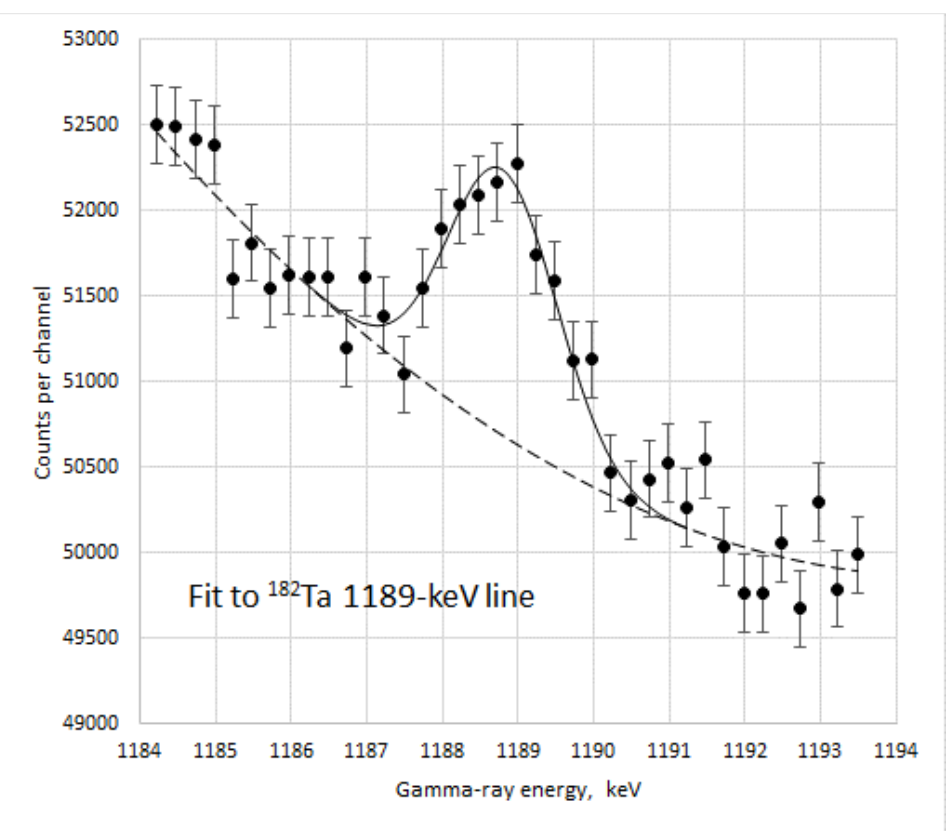


Because the energies of the four ${ }^{182} \mathrm{Ta}$ lines are quite close together and the statistics are not particularly good, it is not possible to exploit the dependence on gamma-ray energy $k$ of the gamma-ray mass attenuation coefficient $\mu / \rho=\mu / \rho(k)$ to extract both activity and absorber thickness as in [4], and so the count rates $C_{i}=\alpha_{i} \exp \left(-\mu / \rho_{\text {steel }}\left(k_{i}\right) \rho_{\text {steel }} t\right) \exp \left(-\mu / \rho_{\mathrm{Pb}}\left(k_{i}\right) \rho_{\mathrm{Pb}} t\right) \varepsilon\left(k_{i}\right) A_{i}$ for the gamma-ray lines $i$ were simply divided by the product of the gamma-ray emission probability $\alpha_{i}$ [9], the attenuation factors for gamma-rays in lead and steel [10], and the HPGe fullenergy-peak detector efficiency $\varepsilon\left(k_{i}\right)$ [11] to give values of activity $A_{i}$. Parameters are given in Table 2, and activities in Table 3.

\begin{tabular}{|ccccc|}
\hline & \multicolumn{2}{c}{ Lead } & \multicolumn{2}{c|}{ Steel } \\
Absorber & $\begin{array}{c}\text { Thickness } \\
\mathrm{cm}\end{array}$ & $\begin{array}{c}\text { Density } \\
\mathrm{g} \mathrm{cm}^{-3}\end{array}$ & $\begin{array}{c}\text { Thickness } \\
\mathrm{cm}\end{array}$ & $\begin{array}{c}\text { Density } \\
\mathrm{g} \mathrm{cm}^{-3}\end{array}$ \\
Flask wall & 17.0 & 11.3 & & \\
Flask outer skin & & & 1.5 & 7.8 \\
Flask inner skin & & & 0.6 & 7.8 \\
Target can wall & & & 0.2 & 7.8 \\
Target pressure vessel walls & & & 1.5 & 7.8 \\
Total thickness, $\mathrm{g} \mathrm{cm}^{-2}$ & \multicolumn{2}{c}{29.6} & \multicolumn{3}{c}{2.1} & \\
\hline
\end{tabular}

91

Table 2. Absorption thicknesses between target core and HPGe detectors. A representative value averaged around the perimeter of the pressure vessel has been taken for the thickness of the pressure vessel walls.

\begin{tabular}{|c|c|c|c|c|c|c|}
\hline $\mathrm{keV}$ & $\mu / \rho_{\mathrm{Pb}}$ & $\mu / \rho_{\text {steel }}$ & $\varepsilon$ & $\alpha$ & cps & GBq \\
\hline \multicolumn{7}{|c|}{ BE2830 } \\
\hline 1121 & 0.0641 & 0.0566 & $9.01 \mathrm{E}-06$ & $35.24 \%$ & $0.0795 \pm 0.0075$ & $29.85 \pm 2.82$ \\
\hline 1189 & 0.0611 & 0.0549 & $8.50 \mathrm{E}-06$ & $16.49 \%$ & $0.0767 \pm 0.0053$ & $34.86 \pm 2.41$ \\
\hline 1221 & 0.0598 & 0.0541 & $8.28 \mathrm{E}-06$ & $27.23 \%$ & $0.1294 \pm 0.0047$ & $27.81 \pm 1.01$ \\
\hline 1231 & 0.0594 & 0.0539 & $8.21 \mathrm{E}-06$ & $11.62 \%$ & $\begin{array}{r}0.0642 \pm 0.0048 \\
\text { Mean }\end{array}$ & $\begin{array}{c}30.02 \pm 2.24 \\
29.0 \pm 6.5\end{array}$ \\
\hline \multicolumn{7}{|c|}{ BE3825 } \\
\hline 1121 & 0.0641 & 0.0566 & $9.74 \mathrm{E}-06$ & $35.24 \%$ & $0.0033 \pm 0.0047$ & $1.15 \pm 1.63$ \\
\hline 1189 & 0.0611 & 0.0549 & $9.24 \mathrm{E}-06$ & $16.49 \%$ & $0.0224 \pm 0.0054$ & $9.36 \pm 2.26$ \\
\hline 1221 & 0.0598 & 0.0541 & $9.03 \mathrm{E}-06$ & $27.23 \%$ & $0.0459 \pm 0.0043$ & $9.05 \pm 0.85$ \\
\hline \multirow[t]{2}{*}{1231} & 0.0594 & 0.0539 & $8.96 \mathrm{E}-06$ & $11.62 \%$ & $0.0263 \pm 0.0044$ & $11.27 \pm 1.89$ \\
\hline & & & & & Mean & $8.0 \pm 2.5$ \\
\hline
\end{tabular}

Table 3. Activities of ${ }^{182} \mathrm{Ta}$ extracted from individual gamma-ray lines as described in the text. For each of the HPGe detectors, the mean value is the weighted mean of the four activity values, and the uncertainty quoted includes 5\% for uncertainty in the HPGe full-energy-peak efficiency and $\pm 0.3 \mathrm{~cm}$ in the thickness of the lead walls of the flask. 
Why are the values of activity for the two HPGe detectors so different? The ratio of the two activities is $3.6 \pm 1.4$, whereas at first sight a ratio of unity might be expected. However, the construction of the target core is such that the tantalum is not distributed uniformly around the core. Figs. 4 and 5 show not-to-scale schematic diagrams of the target core inside the flask. From simple geometrical considerations, in terms of the amount of tantalum that an HPGe detector looking at 1200-keV gamma-rays can 'see' (the mean attenuation length in tantalum of the four ${ }^{182} \mathrm{Ta}$ gamma-rays in Table 3 weighted by their emission probabilities being $10.4 \mathrm{~mm}$ ), one pair of opposite sides of the target core (shown as the sides of the target core in the left-hand part of Fig. 4) has 1.93 times as much 'visible' tantalum as the other pair of opposite sides (shown as the sides of the target core in the right-hand part of Fig. 4). And because the detectors are looking at the target in directions that are different by $90^{\circ}$, the most likely explanation is simply that the BE2830 detector is looking at one of the sides that has approximately twice as much visible tantalum as the other side. But at the same time it must be noted that since the HPGe detectors cannot see more than the mean attenuation length into tantalum, ${ }^{182} \mathrm{Ta}$ at a depth greater than $10.4 \mathrm{~mm}$ inside tantalum is effectively 'invisible'.

If it is assumed that the explanation in the previous paragraph is true, then since each detector can see only the tantalum on the side of the target core facing it, the total visible ${ }^{182} \mathrm{Ta}$ activity would be $2 \times(29.0 \pm 6.5)+2 \times(8.0 \pm 2.5)=74 \pm 14 \mathrm{GBq}$. However, there is the invisible ${ }^{182} \mathrm{Ta}$ activity to be taken into account; again from simple geometrical considerations, the ratio ${ }^{2}$ of the volume of tantalum within the 10.4-mm mean attenuation length of the surface of the target core to the total volume of tantalum within the target core is 0.543 , so that with the inclusion of the invisible activity the total ${ }^{182} \mathrm{Ta}$ activity becomes $(74 \pm 14) \div 0.543=136 \pm 26 \mathrm{GBq}$. Of course, one key assumption has been made in deriving this number, viz that the HPGe detectors are looking in the directions indicated in Figs. 4 and 5, but there is strong support for the essential validity of this assumption, as shown in Sect. 4 below.

\footnotetext{
${ }^{2}$ The total volume of tantalum in the target is $2 \times 644 \mathrm{~cm}^{3}$ (the volume of the two 108.5 -mm-wide sides (each $387.5 \times 108.5 \times 15.32 \mathrm{~mm}$ )) $+2 \times 51 \mathrm{~cm}^{3}$ (the volume of the two 80 -mm-wide sides (each $\left(387.5-12 \times 2\right.$ (the twelve 2 -mm-wide water channels) $\times 80 \times 1.75 \mathrm{~mm}$ )) $+588 \mathrm{~cm}^{3}$ (the volume of the cladding on both sides of the water channels $(12 \times 2 \times(108.5-2 \times 1.75) \times 80 \times 2 \mathrm{~mm})+$ the $22-\mathrm{mm}$ slab at the back $((108.5-2 \times 1.75) \times 80 \times 22 \mathrm{~mm}))=1978 \mathrm{~cm}^{3}$. The volume of tantalum within the 10.4-mm mean gamma-ray attenuation length of the surface is $2 \times 437 \mathrm{~cm}^{3}$ (the two 108.5 -mm-wide sides to a depth of $10.4 \mathrm{~mm})+2 \times 51 \mathrm{~cm}^{3}$ (the two 80 -mm-wide sides) $+97 \mathrm{~cm}^{3}$ (the cladding on both sides of the water channels to a depth of $10.4 \mathrm{~mm}$ from the surface $(12 \times 2 \times 80 \times(2 \times(10.4-1.75)) \times$ $2 \mathrm{~mm})+$ the $22-\mathrm{mm}$ slab to a depth of $10.4 \mathrm{~mm}$ from the surface $(80 \times(2 \times(10.4-1.75)) \times 22 \mathrm{~mm}))=$ $1074 \mathrm{~cm}^{3}$. The ratio of these two numbers is 0.543 .
} 


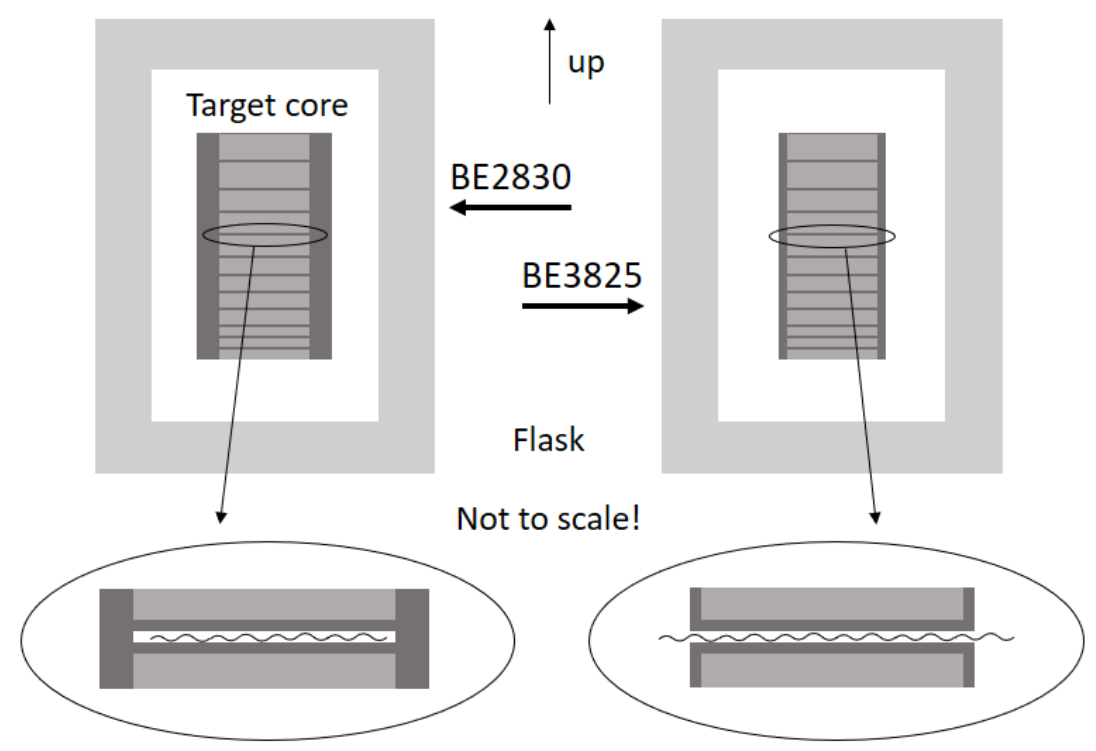

129 Fig. 4. Schematic diagram (not to scale) of the cuboid-shaped target core inside the flask (the surrounding stainless-steel pressure vessel is not shown), looking horizontally in directions different by $90^{\circ}$. Grey, tungsten; dark grey, tantalum; light grey, lead. Expanded regions show one of the cooling-water channels with tantalum cladding between the water and the tungsten. The likely directions in which the two HPGe detectors are looking are indicated.

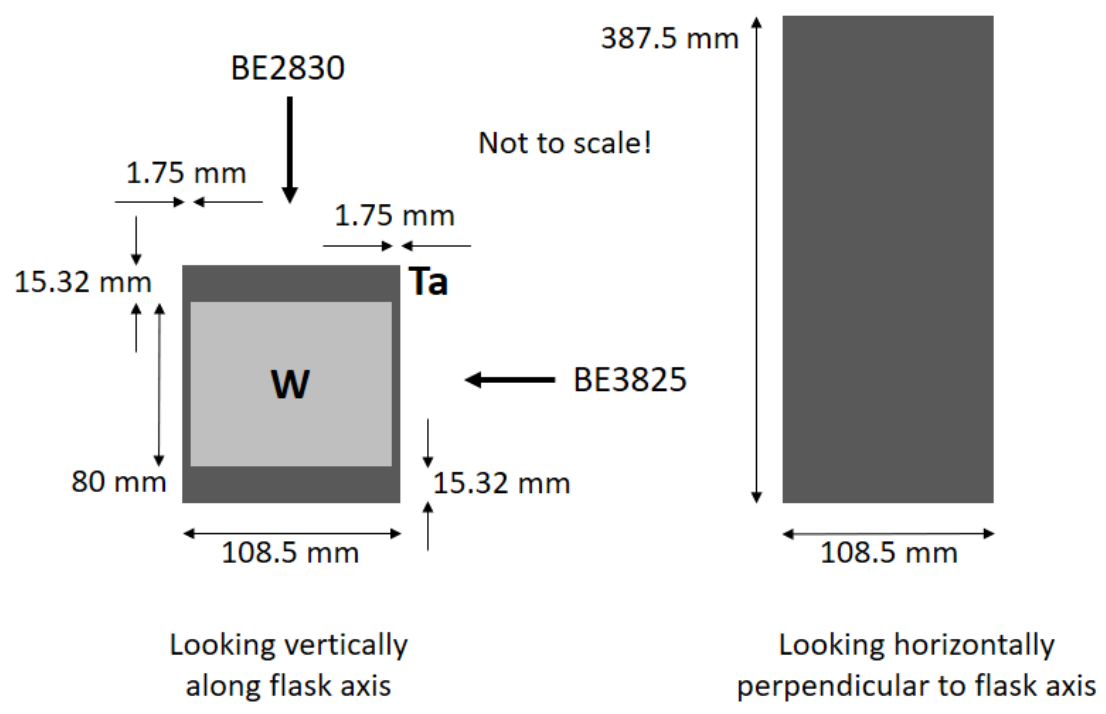

135 Fig. 5. Schematic outline (not to scale) of the cuboid-shaped target core inside the flask (the 136 surrounding stainless-steel pressure vessel is not shown). The interior of the target core also has a tantalum component not shown explicitly: $2 \mathrm{~mm}$ tantalum cladding on each side of the twelve plates (48 mm overall), and a 22-mm slab of tantalum at the very back, a total of $70 \mathrm{~mm}$. The likely directions in which the two HPGe detectors are looking are indicated. 


\section{Calculations}

142 Radionuclide inventories for the TS-1 W\#3 target at May 2019 were calculated using

143 Monte Carlo codes MCNPX 2.70, HTAPE3X and CINDER-90 [12, 13]. The target

144 had been irradiated to 2903 milliamp-hours between May 2009 and August 2014 in

145 twenty-five irradiation campaigns, and the inventory calculations took explicit account

146 of the time sequence of campaigns. The ${ }^{182}$ Ta activity at May 2019 from the Monte

147 Carlo calculations is $163 \pm 12 \mathrm{GBq}$, where the uncertainty given here represents only

148 the statistical uncertainty. The corresponding systematic uncertainty is likely to include

149 contributions from uncertainties in the modelling, from uncertainties in cross-section

150 values used, and, last but not least, from the consequences of choosing particular

151 physics models for use in the MCNPX simulations. In the present work the CEM03

152 model [14] of intra-nuclear cascade and fission-evaporation processes within the

153 MCNPX code was used. Some studies (e.g. [15] and references therein) show

154 significant differences between results obtained with the CEM03 model and results

155 obtained with other models available in MCNPX, such as INCL4/ABLA [16, 17] or

156 Bertini/Dresner [18, 19]. Sensitivity studies [20] within the ISIS TS-1 Project [21]

157 showed that calculated values of useful neutron production at Target Station 1 can vary

158 by up to $15 \%$ depending on the choice of physics model used in the simulations. Taking

159 all these considerations into account, one could conclude that the overall uncertainty in

160 the calculated ${ }^{182} \mathrm{Ta}$ activity is at least $20 \%$.

161 Calculations using the same Monte Carlo codes were also carried out of the relative 162 amounts of ${ }^{182} \mathrm{Ta}$ activity along the length of the surface region of the target (the 163 tantalum sides shown end-on as dark grey in the left-hand side of Fig. 5) and in the 164 interior of the target (the tantalum between each pair of tungsten plates shown in Fig. 4). 165 The results showed that the axial distribution of ${ }^{182} \mathrm{Ta}$ within the tantalum in the target 166 is uniform $^{3}$ to within $6 \%$, thereby underpinning the validity of the assumption made in 167 Sect. 2 for obtaining the total activity of ${ }^{182} \mathrm{Ta}$.

\section{Discussion}

At first sight there is encouragingly good agreement between the measured and calculated values of ${ }^{182} \mathrm{Ta}$ activity: $136 \pm 26 \mathrm{GBq}$ measured, and $163 \pm 12 \mathrm{GBq}$ calculated. But of course one major assumption and several approximations have been made along the way. Nevertheless, support for the validity of the assumption may be obtained from a consideration of the count rates from the two HPGe detectors for the two ${ }^{60} \mathrm{Co}$ lines that dominate the gamma-ray spectra (e.g. in Fig. 2). The specific activity of ${ }^{60} \mathrm{Co}$ in the stainless-steel pressure vessel surrounding the target core can be expected to be essentially independent of the azimuthal angle about the axis of the target core; consequently, if the HPGe detectors are indeed oriented with respect to the target core as has been assumed, the count rates from the detectors should be as set out in Table 4, wherein, from the known dimensions of the pressure vessel, the second column gives the quantities of stainless steel seen by each detector. Since it is evident from the table that agreement between what is expected and what is actually observed is good to $10 \%$, there is neither a reason to believe that the HPGe detectors are misbehaving in any way, nor a reason to believe that there are unexpected azimuthal variations in the thickness of the lead wall of the flask. There is therefore strong support for the

\footnotetext{
${ }^{3}$ It should be noted that there is slight difference in axial uniformity of the ${ }^{182} \mathrm{Ta}$ distribution when going from the front to the back of the target. For the tantalum around the front six and back six target plates the distribution of ${ }^{182} \mathrm{Ta}$ is uniform to within $4 \%$ and $10 \%$ respectively.
} 
interpretation set out in Sect. 2 of the differences in ${ }^{182} \mathrm{Ta}$ line count rates in terms of differences in ${ }^{182} \mathrm{Ta}$ activity presented to the HPGe detectors.

\begin{tabular}{|ccccccc|}
\hline $\begin{array}{c}\mathrm{mm}^{2} \\
\text { per } \\
\text { unit } \\
\text { length }\end{array}$ & $\begin{array}{c}\mathrm{keV}, \\
{ }^{60} \mathrm{Co}\end{array}$ & $\begin{array}{c}\text { Ef- } \\
\text { ficiency }\end{array}$ & $\begin{array}{c}\text { Expected } \\
\text { count } \\
\text { rate }\end{array}$ & $\begin{array}{c}\text { Actual } \\
\text { count rate }\end{array}$ & $\begin{array}{c}(\text { (Expected BE2830) } \div \\
\text { (expected BE3825) } \div \\
((\text { actual BE2830) } \div \\
\text { actual BE3825)) }\end{array}$ \\
BE2830 & 3258 & 1173 & $8.61 \mathrm{E}-06$ & 0.0280 & $36.4 \pm 0.1$ & $1.102 \pm 0.004$ \\
& & 1332 & $7.60 \mathrm{E}-06$ & 0.0248 & $92.5 \pm 0.2$ & $1.083 \pm 0.003$ \\
BE3825 & 2646 & 1173 & $9.36 \mathrm{E}-06$ & 0.0248 & $35.4 \pm 0.1$ & \\
& & 1332 & $8.34 \mathrm{E}-06$ & 0.0221 & $89.3 \pm 0.2$ & \\
\hline
\end{tabular}

\section{References}

214 [1] https://www.isis.stfc.ac.uk.

215 [2] https://www.ornl.gov/project/sns. is valid - as described further in the text. repetition is simply not practical.

\section{Conclusions} activity) was found to be $0.83 \pm 0.17$.

Table 4. Expected relative count rates for the 1173 - and $1332-\mathrm{keV}{ }^{60} \mathrm{Co}$ lines from the two HPGe detectors in the absence of absorption in the flask walls, and actual observed count rates. The second column gives the quantities of uniformly activated pressure-vessel stainless steel seen by the detectors if the detectors are oriented as assumed in the text, and the numbers in the fifth column are the products of the numbers in the second and fourth columns. The numbers in the sixth column are actual observed count rates - including, of course, the effects of gamma-ray-energy-dependent absorption in the flask walls. The fact that the numbers in the rightmost column are close to unity provides good evidence that the ${ }^{182} \mathrm{Ta}$ activity measurement

In an ideal world, of course, the whole measurement process would be repeated with a known orientation of the target inside the flask, but, given the programme priorities and operational constraints of the large accelerator-based user facility that is ISIS, such a

The essential agreement between measurement and calculation of ${ }^{182} \mathrm{Ta}$ activity found in the present work is encouraging in the context of decay heat; in the short to medium term after proton irradiation of the target has ceased, tantalum radioactivity is the single greatest contributor to the thermal decay power dissipated within the target. The agreement between measurement and calculation of ${ }^{182} \mathrm{Ta}$ activity is also encouragingly consistent with the agreement for ${ }^{60} \mathrm{Co}$ and ${ }^{172} \mathrm{Lu}$ previously found in [4].

Activity of ${ }^{182} \mathrm{Ta}$ in a $~ 5$-years-cooled ISIS spallation neutron target has been measured through the thick lead walls of a storage flask using two HPGe gamma-ray detectors. Although the azimuthal orientation of the target within the flask was not known, analyses of the ${ }^{182} \mathrm{Ta}$ and ${ }^{60} \mathrm{Co}$ lines were sufficient to establish the validity of the present measurement. The quotient (measured ${ }^{182} \mathrm{Ta}$ activity) $\div$ (calculated ${ }^{182} \mathrm{Ta}$ 
[4] D J S Findlay, G P Škoro, G J Burns and S Ansell, Appl. Radiat. Isot. 125 (2017) 1. http://dx.doi.org/10.1016/j.apradiso.2017.03.023.

[5] D J S Findlay et al., Nucl. Inst. Meth. A 908 (2018) 91-96.

[6] G M Allen et al., Nucl. Inst. Meth. A 933 (2019) 8-11.

223

224

225

226

227

[9] http://www.nndc.bnl.gov/endf/b7.1/download.html.

228 [10] https://www.nist.gov/pml/x-ray-mass-attenuation-coefficients.

229 [11] D J S Findlay, Radiat. Meas. 94 (2016) 23.

230 [12] MCNPX 2.7.0 - Monte Carlo N-Particle Transport Code System for Multiparticle and High Energy Applications, https://mcnpx.lanl.gov/.

232 [13] W B Wilson and T R England, LA-UR-00-Draft, April 2001.

233 [14] S G Mashnik et al., J. Phys.: Conference Series 41 (2006) 340-351. doi:10.1088/1742-6596/41/1/037.

235 [15] Yu E Titarenko et al., IAEA INDC(CCP)-0453 Report, 2011.

236 [16] A Boudard et al., Phys. Rev. C 66 (2002) 044615.

237 [17] A R Junghans et al., Nucl. Phys. A 629 (1998) 655.

238 [18] H W Bertini, Phys. Rev. 188 (1969) 1711.

239 [19] L Dresner, Oak Ridge National Laboratory Report ORNL-TM-7882 (1981).

240 [20] G P Škoro, ISIS Internal Report, 2016.

241 [21] G P Škoro et al., Physica B: Cond. Matt. 551 (2018) 381-385. https://doi.org/10.1016/j.physb.2017.12.060. 


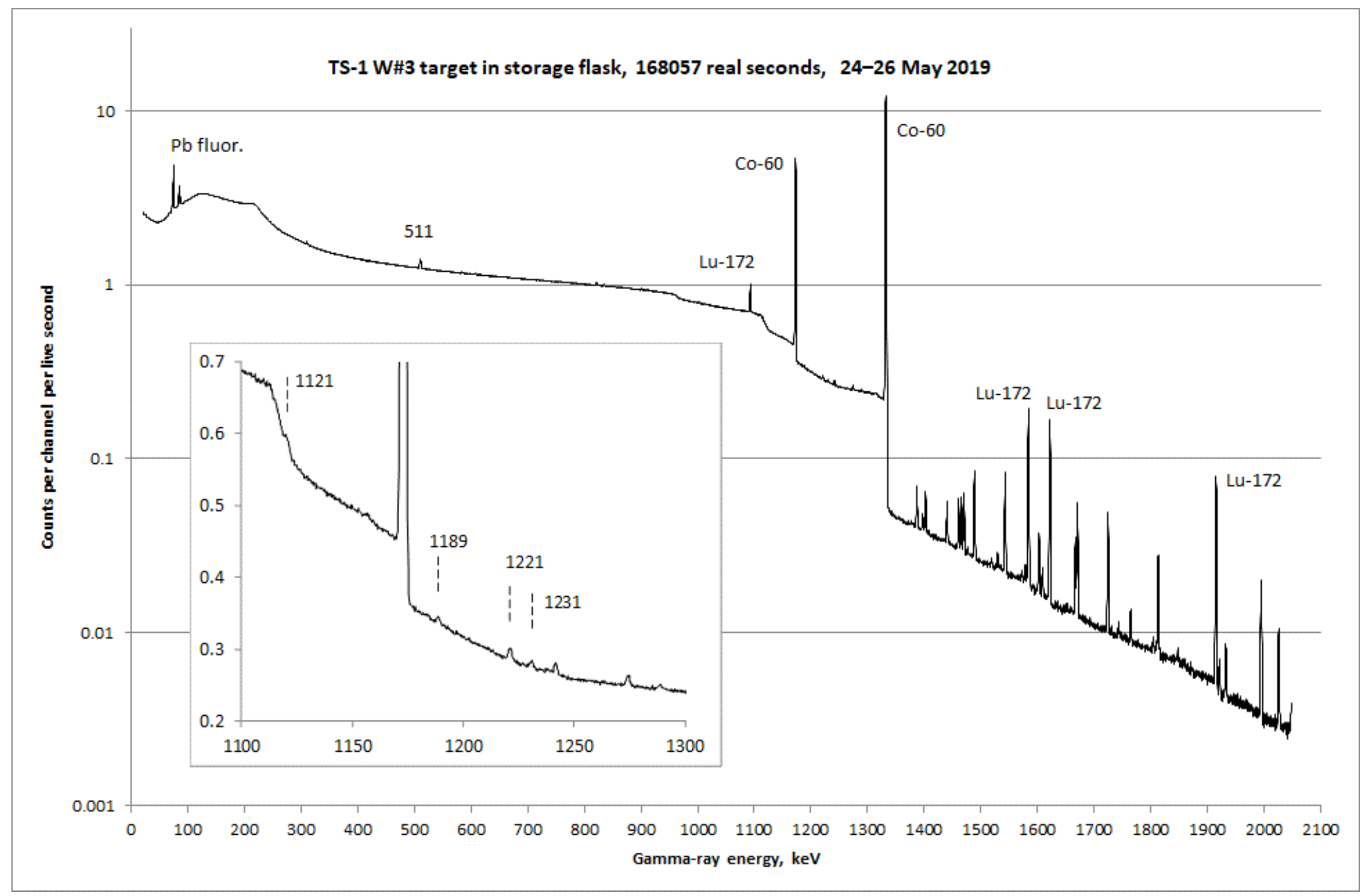

Fig. 2. Gamma-ray spectrum from BE2830 HPGe detector $100 \mathrm{~cm}$ from the surface of the storage flask. The dominant lines are from ${ }^{60} \mathrm{Co}$ and ${ }^{172} \mathrm{Lu}($ for the latter, only a few of the most visible lines are labelled). Apart from $511-\mathrm{keV}$ annihilation gamma-rays and $\mathrm{Pb}$ fluorescence X-rays, no gamma-ray lines below the ${ }^{172} \mathrm{Lu}$ $1094 \mathrm{keV}$ line are visible because of the rapidly increasing attenuation in the $\sim 17$-cm-thick lead flask wall as the gamma-ray energy decreases due to the energy dependence of the gamma-ray mass attenuation coefficient $\mu / \rho$ for lead. The inset shows the four ${ }^{182} \mathrm{Ta}$ lines on which the present paper is based, and their positions. 